\title{
New experimental determination of fatigue strength of tubular truss joints in steel grades up to $\mathrm{S} 690$
}

\author{
S. Herion \& T. Ummenhofer \\ Research Centre for Steel, Timber and Masonry, Karlsruhe Institute of Technology KIT, Germany \\ M. Veselcic \\ CCTH - Competence Center for Tubes and Hollow Sections, Karlsruhe, Germany
}

F. Zamiri \& A. Nussbaumer

Swiss Federal Institute of Technology Lausanne, ICOM - Steel Structures Laboratory, Lausanne, Switzerland

\begin{abstract}
In this paper research work on welded butt weld connections between hot-rolled seamless tubes and steel castings are presented. Comparison is made between different weld preparations for the butt welds including different steel grades, repair methods, the influence of residual stresses and a study on large scale trusses. The steel grades investigated include S550QH as well as S690QH to complement previous test results on lower steel grades. These investigations are intended to lead towards the development of a concept for improving the fatigue life for bridges using such end-to-end connections.
\end{abstract}

\section{INTRODUCTION}

The outcome of two research projects funded by CIDECT and FOSTA (a national steel research funding organization in Germany) were presented at previous ISTS conferences, at ISTS-12 in Shanghai (2008) by Veselcic et al. and at ISTS-13 in Hong Kong (2010) by Nussbaumer et al.

Due to the very convincing results from these projects an extension of the work was carried out by a research group consisting of ICOM of EPFL Lausanne, the Competence Center for Tubes and Hollow Sections (CCTH), Karlsruhe, the Büro für Ingenieurarchitektur Dietrich in Traunstein and the Karlsruhe Institute of Technology KIT. The project was called "P816 - Optimal application of hollow sections and cast steel nodes in bridge building with the usage of steel S355 up to S690" and, as the previous project, sponsored by the German Forschungsvereinigung für Stahlanwendung FOSTA in Düsseldorf. The fatigue classes in both preceding projects were determined on the basis of a lower bound of the experimental dataset due to the little number of available results. To obtain more results and thus to enlarge the dataset for statistical evaluation, additional tests on previously investigated steel grades $\mathrm{S} 355 \mathrm{~J} 2 \mathrm{H}$ and S460NH were carried out.

Additionally, new cast to CHS girth welded test specimens made of hot-rolled seamless hollow sections of steel grades S550QH and S690QH and the matching cast steel material were produced. The specimens were tested under 4-point bending as well as within complete truss girders. With this enlargement of the fatigue test database the influence of several parameters such as steel grade and tube thickness can be assessed.
This paper summarizes the whole project and presents the test results and the re-evaluated S-Ncurves. One major finding is the confirmation of the relative independence of steel grade (from both CHS and cast steel) on the fatigue strength of end-to-end connections in tubular truss joints.

All these investigations will help allow for safer and more economical design of bridges made of thick-walled hollow sections and cast nodes.

\section{RESEARCH PROJECT}

\subsection{Overview}

Based on the previous project the new research work was planned as a combined work of Karlsruhe Institute of Technology (KIT) and EPFL Lausanne. With this it was possible to investigate a lot of different aspects on test specimens under fatigue loading of tube to tube connections between cast steel joints and steel hollow sections.

Not all aspects of the research project are included in this paper, namely: architectural aspects of tubular bridges which were studied by the office of engineering-architecture Richard Dietrich, "integral planning" of bridges made of tubular steel structures which was enhanced and time-tested and the economical aspects of material, welding, nondestructive-testing, etc. which were also studied.

In this way, the economic value for the erection of such structures can be optimized and therefore a realization in practice will be promoted. 


\section{ANALYSIS OF BUTT WELDED JOINTS}

\subsection{Overview}

Butt welds are used in bridge constructions in multifaceted varieties as a connection of two chords or between cast steel joint and steel tube. These connections are butt welds with or without weld backing. All welds can be carried out as single side welds only. Within the scope of this project different variants for butt weld designs are investigated.

Since the chemical as well as the mechanicaltechnological properties of the used cast steel parts are nearly the same as for the hot-rolled hollow sections, all following assumptions are not only valid for butt welds between hollow sections and cast steel parts but furthermore for butt welds connecting hollow sections also.

The tests carried out on butt-welded specimen have been performed in close cooperation between Karlsruhe Institute of Technology (KIT) and the Center of competence for tubes and hollow sections $(\mathrm{CCTH})$. On the basis of the test results derived from project P591(2010) and in close collaboration with EPFL Lausanne and the involved participants of the industry in the monitoring group of the project the research program for the examination of the butt welds was proposed. The objective was to reduce the previously investigated variants to the decisive ones and maintain a wide spectra of possible butt welded joints to perform an economic feasibility study with the different variants.

In the first part the testing program with the different variant is presented. Subsequently the chosen materials are given and the fabrication of the test specimens is described. Special attention is placed on the non-destructive examinations. Furthermore, repair welding on different test specimens is considered. One of the main aspects of the project was on the investigation of high strength steels. These test results are illustrated with a detailed analysis.

Furthermore, FE-calculations concerning the influence of the different wall-thicknesses and geometries have been performed. However, these results are not part of this paper.

\subsection{Testing Program}

Detailed information on the manufacturing processes was presented in former publications mentioned above. Details on quality levels and welding parameters mentioned in this section are described in detail in Veselcic et al. (2006, 2007, 2009).

For the research projects steels according to Table 1 are considered for the tests. With the use of high strength steel, a reduction of the member thickness can be realized in practice. To ensure good weldability, the cast quality is chosen according the previous projects. For the welding, pre-heating was

only used for the steel grade S690. For all other steel grades pre-heating could be omitted, which entails a significant cost reduction.

Table 1. Steel Grades for the Hollow Sections and corresponding Cast Steels

\begin{tabular}{llll}
\hline Hollow Sections & Standard & Cast Steel & Standard \\
\hline S355J2H & EN 10210 & G20Mn5(V) & EN 10293 \\
S460NH & EN 10210 & G10MnMo V 6-3 & EN 10293 \\
\hline S460NH & EN 10210 & G10Mn7V & EN 10293 \\
\hline S550QH & prEN 10210 & G10Mn7V & EN 10293 \\
\hline S690QH & EN 10210 & G10MnMo V 6-3 & EN 10293 \\
\hline
\end{tabular}

Altogether, four butt weld solutions have been condensed from the previous project (see figure 1). The testing programme for all four solutions was identical.

A summary of the section dimensions of all tests on butt welds is given in Table 2. The influencing factors studied were the diameter and thickness of the tubular beams and the detailing of the CHScastings butt welds. In solution 2 the cast steel wall thickness is chosen to be the same size as that of the hollow section to be welded to it. For the other solutions $10 \mathrm{~mm}$ is added to the cast steel components.

All fatigue test specimens were made out of two CHS and one cast steel member, forming tubular beam specimens. The tests were carried out under 4point bending as shown in Figure 2. Altogether 32 tests have been performed on high strength steel.

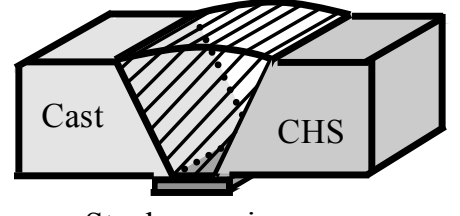

Steel snap ring

Solution 2 : backing using steel ring

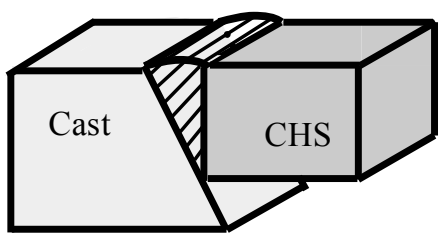

Solution 5 : no backing ring and not beveled

Figure 1. The four different variants of butt weld solutions studied.

After welding the test specimens, an ultrasonic inspection of the different variants is carried out to detect any defects. However, for practical applications, it should be pointed out that with a multitude of regulations for ultrasonic inspection, the necessary requirements should be specified at an early stage of a project to avoid subsequent disagreements between the client and contractor and to maintain quality standards. 
Table 2. Testing Program for all four solutions

\begin{tabular}{ccccc}
\hline $\begin{array}{c}\text { Outside di- } \\
\text { ameter } \\
\varnothing \mathrm{mm}\end{array}$ & $\begin{array}{c}\text { Cast steel wall } \\
\text { thickness } \\
\mathrm{mm}\end{array}$ & $\begin{array}{c}\text { CHS wall } \\
\text { thickness } \\
\mathrm{mm}\end{array}$ & No. of tests & $\begin{array}{c}\text { Steel } \\
\text { grade }\end{array}$ \\
\hline \multirow{2}{*}{193.7} & $20 / 30^{*}$ & 20 & 2 & $\mathrm{~S} 460$ \\
298.5 & $30 / 40 *$ & 30 & 2 & $\mathrm{~S} 690$ \\
\hline
\end{tabular}

* depending on chosen solution

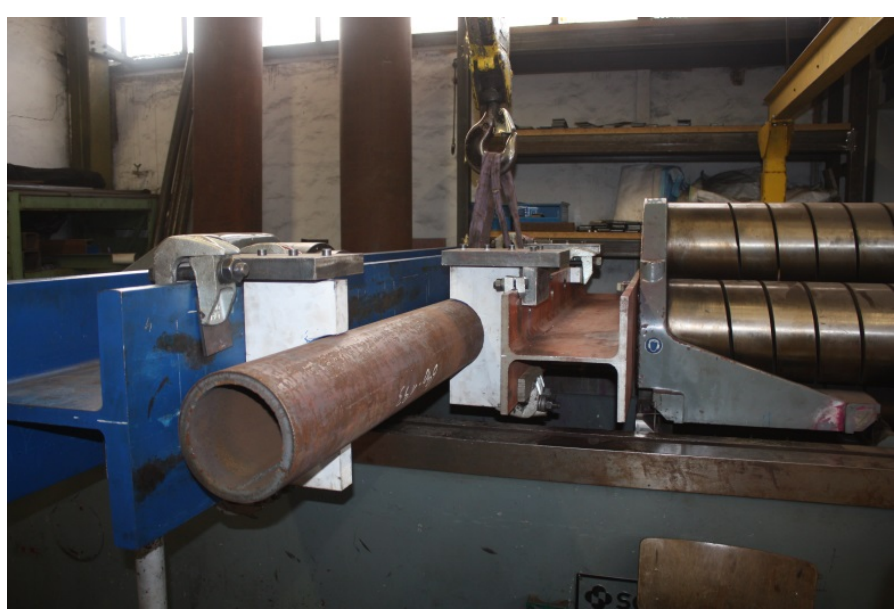

Figure 2. Test rig for 4-point bending fatigue tests on beam specimens diameters 193.7 and $298.5 \mathrm{~mm}$.

For the investigations three main aspects were taken into account.

The first aspect was an extension on the existing data concerning steel grades with $\mathrm{f}_{\mathrm{y}}=355 \mathrm{MPa}$ and $\mathrm{f}_{\mathrm{y}}=460 \mathrm{MPa}$. For this, additional to the tests of specimens made of S460, further tests with steel grades S550 and S690 have been performed. These steel grades were also realized for the cast steel parts. With this a large scope, also with respect to future constructions could be covered.

Secondly, failed beam specimens from the preceding project were repaired and examined again. Further tests on the available specimens can lead to an extended fatigue life and higher detail categories. Additionally, the fatigue resistance of the repaired weld should be investigated. With repair welding, the life expectancy of bridge structures can be extended.

\subsection{Tests on repair welded beam specimen}

On test specimens previously tested repair welding should be conducted to study the influence of a repaired weld. Furthermore, as always two welds were simultaneously tested with only one failed in the tests, another test result can be obtained for the weld that not failed yet.

Prior to the selection of the specimens to be repair welded all suitable specimens have been ultrasonically tested. Based on this the specimens with small defects in the still intact weld could be excluded Only the specimens with none or small defects are taken into account for repair. Otherwise the weld would crack before the repair welded weld has any significant cycles to fatigue. The failed weld was tested with magnetic particle testing to obtain the full length of the existing crack. For repairing the crack was grind to provide a good quality.

After repair welding the fatigue tests were continued. The parameters used previously have not been changed. In total, 4 fatigue tests (with 4 repaired welds and 4 still intact welds) were performed. The test frequency was between $20 \mathrm{~Hz}$ and $30 \mathrm{~Hz}$ (depending on the stiffness of the specimen) with a load ratio $\mathrm{R}=\mathrm{Q}_{\min } / \mathrm{Q}_{\max }$, of 0.2 .

For each test, further applied cycles to fatigue the specimen was determined. The tests were stopped when either the repaired weld or the previously intact weld cracked. For two test specimen a crack occurred in both welds. For these specimens the repaired weld featured lower cycles to fatigue as for newly welded welds.

Both other test specimens showed a crack only in the previously intact weld. The endured cycles to fatigue was more than $50 \%$ higher than previously obtained. Die test results for all specimens are presented in Table 3. A proposal concerning further fatigue life of repair welds could not be derived based on only two test results. For this further tests are necessary.

Table 3. Test results on beam specimens after repair welding

\begin{tabular}{cllclc}
\hline specimen & $\begin{array}{c}\text { previous } \\
\text { cycles of fatigue }\end{array}$ & $\begin{array}{c}\text { Loading } \\
\mathrm{S}_{\mathrm{R}}\end{array}$ & $\begin{array}{c}\text { Repaired weld } \\
\text { cycles of fatigue }\end{array}$ & $\begin{array}{c}\text { Intact weld } \\
\text { cycles of fatigue }\end{array}$ & crack \\
\hline V3-B1 & 1.193 .693 & $170 \mathrm{MPa}$ & 232.365 & 1.426 .058 & Both \\
V5-B1 & 1.838 .046 & $170 \mathrm{MPa}$ & 255.735 & 2.093 .781 & Both \\
V5-B2 & 209.471 & $233 \mathrm{MPa}$ & 153.069 & 362.540 & Existing weld \\
V6-B1 & 434.024 & $170 \mathrm{MPa}$ & 226.188 & 660.212 & Existing weld \\
\hline
\end{tabular}




\subsection{Test in high strength steel}

For all fatigue tests specimens with two welds have been investigated. All fatigue tests have been stopped, when a crack through the wall-thickness (through crack) was visually observed. All failures for tests observed started from inside at the weld root with the crack propagating in the weld area or the heat affected zone.

In total, 32 fatigue tests (with 64 welds altogether) were carried out at load ratios $R=Q_{\min } / Q_{\max }$, of 0.2 .

\subsection{Evaluation of test results}

All fatigue classes determined in the evaluation are only suggested as a lower bound of the experiments due to the number of available testing data. With more experimental results using the existing and only partially broken test specimens.

Since the specimens contained two butt welds, the results are biased towards the weaker joint, allowing a conservative safety margin for the evaluations. Also, since in the bending tests only part of the joint is subjected to the highest stress ranges and the weld root is less loaded, the expected fatigue life is obviously higher than in the case of tension tests, where the weakest joint part will fail first.

The failure criteria used for determining S-N curves is through-thickness cracking. As expected, the bending tests give good fatigue strengths, with characteristic nominal stress range values at 2 million cycles, $\Delta \sigma_{C}$, ranging between 100 and 120 $\mathrm{N} / \mathrm{mm} 2$ and a fatigue slope coefficient $\mathrm{m}=5$.

The fatigue test results are summarized in Table 4. Here not only the test results obtained in this project are described but furthermore they are compared with the previous results.

It is notable that for welding the high strength steel the correspondent filler material is chosen respectively. For some tests however the filler material used had lower yield strength. In an evaluation of all specimens no negative effect of the yield strength was observed. The evaluation of the specimens with filler material of lower yield strength leads to a higher detail category in comparison to the specimens with adequate yield strength. Therefore the filler material had only a small or nearly no influence on the test results.

According to Eurocode 3, part 1-9 (2005), only solution 2 (see Table 4, grey marked section) can directly be classified. It is a transverse butt weld, full penetration, between curved plates (EN1993-1-9, Table 8.3, detail 14), with a fatigue strength or corresponding detail category of $71 \mathrm{~N} / \mathrm{mm} 2$ and $\mathrm{m}=3$ (with size effect reduction if $\mathrm{t}>25 \mathrm{~mm}$ ). Note that these joints cannot be classified using EN1993-1-9, Table 8.6 (hollow sections), detail 3, since here the allowable range is only for $\mathrm{t}<12.5 \mathrm{~mm}$. All tests and statistical analyses show higher slopes, usually closer to $m=5$.

Solution 2 and 5 in both projects give comparable results. With this no difference in steel quality concerning the fatigue life is observed. The other solution 3 and 5 give slightly lower results (approximately $5 \%$ ).

Table 4. Test results for all solutions on butt welds.

\begin{tabular}{|c|c|c|c|c|c|}
\hline \multirow{3}{*}{ Solution } & \multicolumn{2}{|c|}{ Project P591 } & \multicolumn{3}{|c|}{ Project P816 } \\
\hline & $\begin{array}{c}\text { lower } \\
\text { boundary }\end{array}$ & $\begin{array}{l}\text { Number } \\
\text { of tests }\end{array}$ & $\begin{array}{c}\text { lower } \\
\text { boundary }\end{array}$ & $\begin{array}{l}\text { Addition- } \\
\text { al test } \\
\text { results }\end{array}$ & $\begin{array}{c}\text { Total } \\
\text { test } \\
\text { results }\end{array}$ \\
\hline & $\Delta \sigma_{C}$ and $m$ & & $\Delta \sigma_{C}$ and $m$ & & \\
\hline 1 & $122(m=5)$ & 4 & - & - & 4 \\
\hline 2 & $119(m=5)$ & 14 & $120(m=5)$ & 8 & 22 \\
\hline 3 & $128(m=5)$ & 4 & $120(m=5)$ & 9 & 13 \\
\hline 4 & $130(m=5)$ & 4 & - & - & 4 \\
\hline 5 & $113(m=5)$ & 14 & $105(m=5)$ & 10 & 24 \\
\hline 6 & $100(m=5)$ & 12 & $100(m=5)$ & 9 & 21 \\
\hline
\end{tabular}

In a first analysis, the results on the different steel grades were pooled together, i.e. it was agreed that there was no significant difference in fatigue behavior between the different steel grades. Also, all specimen sizes could be pooled together as no significant size effect was noticed apart from the effect of additional bending due to misalignment. (see also Nussbaumer et al. 2013).

Table 5. parameters of the evaluation for different steel grades

\begin{tabular}{ccccc}
\hline Steel grade & $\begin{array}{c}\text { calculated } \\
\text { slope } \mathrm{m}\end{array}$ & $\begin{array}{c}95 \% \text { survival probabil- } \\
\text { ity }\end{array}$ & $\begin{array}{c}\text { Difference between mean stress } \\
\text { to } 95 \% \text { survival probability }\end{array}$ & $\begin{array}{c}\text { Stress range } \mathrm{S}_{\mathrm{R}} \text { as lower boundary of } \\
\text { test results }\end{array}$ \\
\hline & & {$\left[\mathrm{N} / \mathrm{mm}^{2}\right]$} & in $\%$ & {$\left[\mathrm{~N} / \mathrm{mm}^{2}\right]$} \\
S355 & 6,5 & 109,8 & 17 & 100 \\
S460 & 5,4 & 111,1 & 23 & 110 \\
S550 & 3,6 & 72,8 & 38 & 105 \\
S690 & 6,8 & 126,5 & 18 & 110 \\
\hline
\end{tabular}


However, in a second analysis the test results have been evaluated according to their steel grades (S355, S460, S550 and S690). With this all test results for one steel grade have been pooled together for evaluation. The parameters of this evaluation are presented in table 5 .

It stands out that in the statistical evaluation the difference of the $95 \%$ survival probability compared to the mean stress for the steel grades S355, S460 and S690 is roughly $20 \%$, with a minimum characteristic value of approx. $110 \mathrm{~N} / \mathrm{mm}^{2}, \mathrm{~m}=5.4$. In the case of S550 the difference is nearly $40 \%$. This could possibly be attributed to defects in the welding. Furthermore the small number of tests has to be taken into account. The slope ended up with $\mathrm{m}=3.6$ which also gives the impression that there have been some problems with the welding. In all other cases the slope is between $\mathrm{m}=5.4$ and 6.8 .

Of particular concern is the lower boundary of the test results. The stress variation range is lower for the steel grade 550 compared to the other steel grades. This is due to the higher variation.

A complete evaluation of all test results is presented in figure 3. In total, there are 108 individual test results put together for the evaluation. For all test specimens there are two test results available one concerning the failed weld and one for the nonfailed weld. In cases where both welds have failed both test results have been considered.

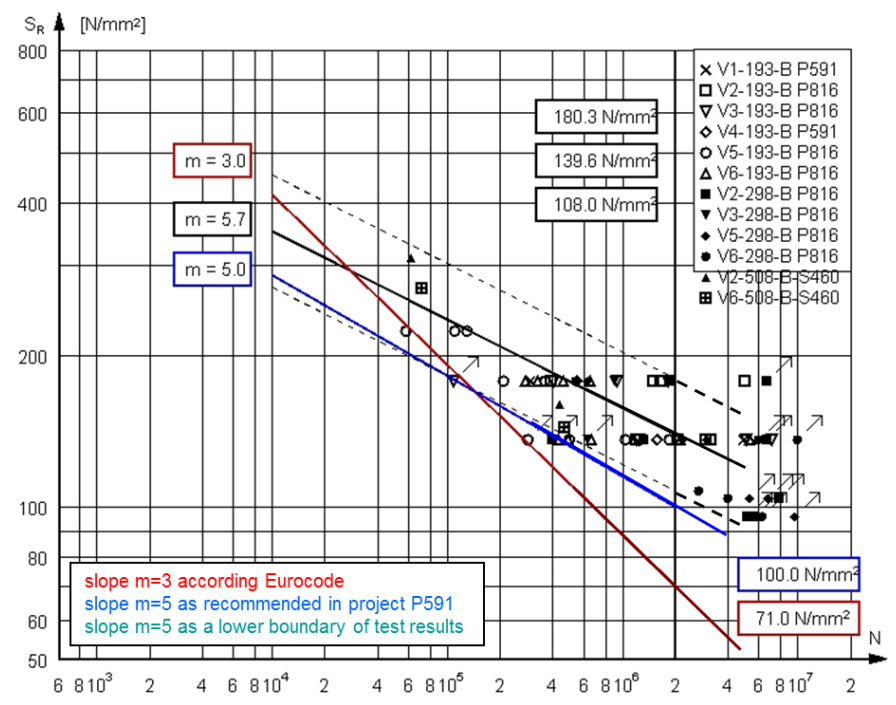

Figure 3. S-N curve of complete test results

Assuming a slope of $m=5$ a lower boundary for all test results can be derived which leads to a detail category of 100 . This graph is almost identical with the graph $95 \%$ survival probability with a slope of $\mathrm{m}=5.7$ determined in the statistical evaluation.

\section{STUDY ON LARGE-SCALE TRUSSES AND THEIR WELDING RESIDUAL STRESSES}

\subsection{Testing program}

Since one crucial point differentiating small (in this case beam specimens) and large-scale tests (truss girders) is the residual stress field present in the fatigue cracking region, emphasis is put on measuring them and accounting for them. Thus the experimental program consisted in two separate studies:

determination of residual stresses in $\mathrm{K}$-joints made out of S690 (using neutron diffraction facilities at ILL, Grenoble), in order to compare with those measured on S355 K-joints,

- fatigue tests on 2 large-scale truss girder with $\mathrm{K}$-joints in S 690 and including matching cast tube parts, in order to verify the fatigue behavior observed on the beam test specimens.

\subsection{Results on residual stresses}

The largest measured residual stresses in K-joints made out of S690 were about $60 \%$ of the yield stress in the direction transverse to the weld bead. Compared with previous measurements on S355, the residual stress field is found not to be a function of the yield stress, which is in opposition with BS 7910 . An example of the measurement results is shown in Figure 4. As can be seen, the measurements in the transverse to the weld bead, for the most part, fall within the band from BS 7910 and also follow its trend given in function of the depth from the surface. The longitudinal components of the stresses show the same trend, the radial being of less interest (the values in this direction were relatively low).

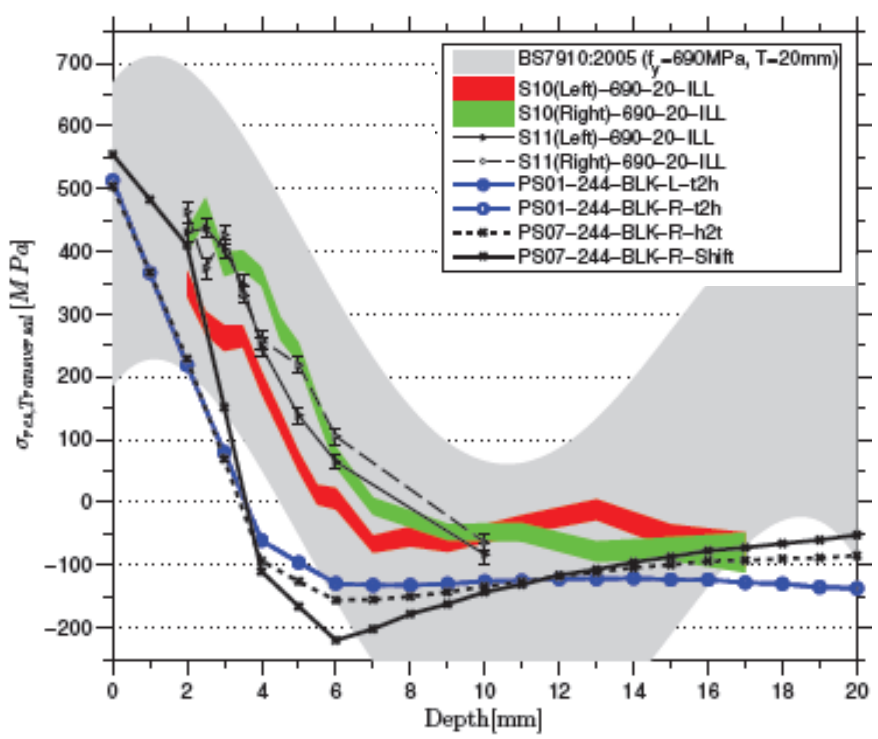

Figure 4. Transverse residual stresses from measurements and computations

As shown on Figure 4, welding simulations with a simplified $\mathrm{nb}$ of passes, but considering phase transformations, were also carried out and gave val- 
ues and a trend globally similar to the measured values. Also, the values at the left and right toes were found to be very similar, even if influenced by the start position.

\subsection{Trusses fatigue tests}

Similar tube sizes and truss size as in the previous studies were used, namely upper and lower chords were 193.4 x $20 \mathrm{~mm}$ circular hollow sections and braces were $101.6 \times 8 \mathrm{~mm}$. The trusses were $9.66 \mathrm{~m}$ in length and $1.97 \mathrm{~m}$ in height. Keeping the size also provided a more convenient comparison between the specimens. In particular, the eccentricity ratio was kept close to the values used in specimens S5 to S7 tested during P591 (P591, 2010). In addition to the $\mathrm{K}$-joints and next to them, cast nodes were introduced. They were made like tubes parts in order to get butt joints between them and the tubes. They were 20 and $30 \mathrm{~mm}$ thick and made out of G10MnMoV6-3.

A three-point load-controlled bending test setup similar to experiments previously done was employed. The tests were carried out at constant amplitude and with a load ratio $\mathrm{R}$ equal to 0.1 . The loading frequencies, were selected as $1.8 \mathrm{~Hz}$ and $1.3 \mathrm{~Hz}$ for S10 and S11, resp. Cyclic loading was stopped at regular intervals to repeat the static tests and crack detection. After the failure of the first joint in each truss, the tests were stopped temporarily to carry out the repair operation and then the cyclic loading continued. A rapid repair method using post-tensioning - which did not require dismounting the truss from the test platform- was successfully applied to the trusses. Truss S11 was tested first; the test lasted 516000 cycles. Afterwards, truss S10 was tested with a lower load range up to 1949000 cycles.

Nominal stresses in truss joints were numerically evaluated using a beam element structural model. From previous studies, the following modeling procedure was found to give most accurate results:

- Nodal eccentricities are simulated by rigid links

- For section properties of brace elements in the connection region, the real section is used instead of rigid section properties.

- Brace moments are evaluated at brace-to-chord surface intersection.

Measurements of the strains were also carried out. Experimentally determined were generally in agreement with the numerical values. Hot-spot stresses at the joints were calculated by multiplying axial and bending stresses in the joint by relevant stress concentration factors (SCF). However, the formulas from the CIDECT recommendations were not used since geometric parameters of test trusses are outside the application range for SCF tables given by Zhao et al. [CIDECT recommendations, 2000]. Instead, SCF tables provided in publication [VSS578 2004] were used for calculation of the
SCF. These tables were the result of an extensive parametric study at a parameter range more suitable for bridge application. structures $(0.5 \leq \beta \leq 0.7,4 \leq \gamma$ $\leq 12$, and $0.3 \leq \tau \leq 0.7$, with realistic consideration of nodal eccentricities in FE models). Using these SCF, the values of the hot spot stresses determined from the nominal ones are the closest to the real values (extrapolated at hot spot from strain meas.).

For the K-joints, no difference was observed, nor in the behavior neither the fatigue strength, between S690 trusses and S355 trusses previously tested. Thus, the same fatigue category can be used for both steel grades. The trusses systematically failed from the K-joints, i.e. for the load combination applied, the $\mathrm{K}$-joints have a lower fatigue strength compared to the cast to tube butt joints. Thus only run-outs but no failures resulted form the fatigue tests on the cast to tube butt joints. Subsequent NDE by KIT on some of the joints using phased-array method confirmed that no fatigue crack initiated in these joints. A couple of the run-outs are below but near to the curve $\Delta \sigma \mathrm{Ct}=71, \mathrm{~m}=5$, which is a logic confirmation that for these load levels and number of cycles no fatigue cracks should be found.

\section{SUMMARY AND CONCLUSIONS}

Experimental studies were initiated with the aim of establishing design recommendations for the fatigue behavior of end-to-end connections. Especially the previously derived detail categories for material S355 and S460 were examined using higher steel grades up to $\mathrm{S} 690$.

To obtain this, four variants of butt-welded connections had been determined to be investigated on high strength steel. Furthermore, repair welding has been performed on selected test specimens. All fatigue tests have been carried out either as 4-point bending tests on beam specimens or 3-point bending on the trusses. The results obtained on beam specimens have thus been verified on large scale truss girder tests. All experimental data have been evaluated according Eurocode 3 and using S-N curves with a slope $\mathrm{m}=5$.

The following conclusions can be drawn from this program combined with the previous ones:

- For the beam specimens, some difference between steel grades was observed. For the steel grades S355, S460 and S690, this difference in the $95 \%$ survival probability compared to the mean stress was roughly $20 \%$, with a minimum characteristic value of approx. $110 \mathrm{~N} / \mathrm{mm}^{2}, \mathrm{~m}=$ 5.4. Only S550 gave worse results, but number of results is very limited so not conclusive.

- There was no difference in results for trusses made of S355 and S690. For all tests there was a failure on the K-joints. No failure was observed from the butt welded joint, the run-outs being in 
agreement with results from the beam tests. There is thus a lower fatigue strength of the $\mathrm{K}$ joint compared to butt welded joint.

- For tubular bridge constructions made of CHS and cast steels, the obtained fatigue classifications for butt-welds are also applicable to high strength steels up to S690, a summary of the detail categories is given in table 6 as a proposal for design recommendations and regulations.

- The K-joints made out of S690 showed residual stresses about $60 \%$ of the yield stress in the direction transverse to the weld bead. The absolute values are close to previous measurements on S355, thus the residual stress field is found not to be a function of the yield stress, which is in opposition with BS 7910.

In this paper, structural hollow sections in bridge construction are shown to meet the project goals: functionality, aesthetics, durability, and economic viability.

\section{ACKNOWLEDGMENTS}

The authors gratefully acknowledge the financial support of FOSTA (Forschungsvereinigung Stahlanwendung e.V.) and CIDECT for these investigations. The authors would also like to thank the members of the working group for the research project P816 "Optimal application of hollow sections and cast steel nodes in bridge building with the usage of steel S355 up to S690". Thanks are also addressed to the companies who participated in this project, ROPROTEC GmbH, Maurer Söhne, Schmitt Werkstoffprüfung, Friedrich WilhelmsHütte, Vallourec Deutschland $\mathrm{GmbH}$, Brütsch/Rüegger AG (Schweiz), Zwahlen et Mayr S.A. (Schweiz).

Table 6. Summary of proposed new S-N curves for tubular bridge construction made of structural steels up to $\mathrm{S} 690$.

\begin{tabular}{|c|c|c|c|}
\hline Detail category* & Detail & Description & Requirements \\
\hline & & \multirow{6}{*}{$\begin{array}{l}\text { Butt-joint between CHS and cast } \\
\text { steel with backing made of ceram- } \\
\text { ic elements or a steel ring }\end{array}$} & Weld must be UT controlled. \\
\hline$\Delta \sigma_{C b}=112$ & & & The cast steel meets a quality level V1S1 \\
\hline$\Delta O_{C b}-112$ & & & at its ends, with NDT control on surface \\
\hline \multirow{3}{*}{$\begin{array}{c}\Delta \sigma_{C t}=71 * * \\
(m=5)\end{array}$} & & & cracks. Tube slenderness: $\gamma \leq 5.0$ \\
\hline & & & Minimum wall thickness $T \geq 20 \mathrm{~mm}$ \\
\hline & & & Maximum wall thickness $T \leq 60 \mathrm{~mm}$ \\
\hline
\end{tabular}

Butt-joint between CHS and cast
steel with different thicknesses:
- beveled, with tack welded
backing steel ring $(t=3$ to
4 mm) or ceramic backing
- with TIG root pass as backing
Butt-joint between CHS and cast $k_{f}=\left(1+\frac{6 e}{T_{1}} \frac{T_{1}^{1.5}}{T_{1}^{1.5}+T_{2}^{1.5}}\right)$ with $T_{2}>T_{1}$
steel with different thicknesses and CHS not beveled, with or without backing

Minimum wall thickness $T \geq 20 \mathrm{~mm}$

Maximum wall thickness $T \leq 60 \mathrm{~mm}$
Weld must be UT controlled.

The cast steel meets a quality level V1S1 at its ends, with NDT control on surface cracks.

Tube slenderness: $\gamma \leq 5.0$

The thickness variation should not exceed $T_{1} / T_{2}>0.6$

Account for secondary bending correction using

$\Delta \sigma_{C, h s}=80(m=3)$

Welded K-joint

For chord wall thicknesses $\mathrm{T}>16 \mathrm{~mm}$, account for size effect using Equation (2)

\footnotetext{
* expressed in nominal stress range, $\Delta \sigma_{C}$ (index b for bending or $\mathrm{t}$ for tension), or hot spot stress range, $\Delta \sigma_{C, h s}$

** detail category 71 was temporarily predefined as a lower bound. Conservative estimation because a lot of test specimens did not fail
} 


\section{REFERENCES}

Veselcic, M., Herion, S., Puthli, R. (2003). "Cast steel in tubular bridges - New applications and technologies," Proceedings of the 10th International Symposium on Tubular Structures; Swets \& Zeitlinger, Lisse, Netherlands

MacDonald, K.A. and Maddox, S.J., (2003). New guidance for fatigue de-sign of pipeline girth welds, Engineering Failure Analysis , Elsevier science Ltd., No. 10, pp. 177-197.

Veselcic, M., Herion, S., Puthli, R. (2006). "Selection of buttwelded connections for joints between tubulars and cast steel nodes under fatigue loading," Proceedings of the 11th International Symposium on Tubular Structures; Taylor and Francis, London, United Kingdom

Schumacher, A. and Nussbaumer, A., (2006). Experimental study on the fatigue behavior of welded tubular k-joints for bridges. Engineering Structures, Vol. 28, pp. 745-755.

Herion, S. (2007). "Guss im Bauwesen," Sonderdruck aus Stahlbau Kalender 2007, Ernst \& Sohn

Veselcic, M., Herion, S., Puthli, R. (2007). "Cast Steel and Hollow Sections - New Applications and Technologies," Proceedings of the 17th International Offshore and Polar Engineering Conference (ISOPE-2007), Lisbon, July 1-7, 2007

Herion, S., Veselcic, M., Puthli, R. (2007). "Cast steel - new standards and advanced technologies" 5th International Conference on Advances in Steel Structures, Singapore

Haldimann-Sturm, S., Nussbaumer, A., (2008). Determination of allowable defects in cast steel nodes for tubular bridge applications, International Journal of Fatigue, Elsevier Ltd., vol. 30 , pp. $528-537$.

Nussbaumer, A. and Borges, L., (2008). Size effects in the fatigue behavior of welded tubular bridge joints, Materialwissenschaft und Werkstofftechnik, Wiley interscience, Vol. 39, $\mathrm{N}^{\circ} 10$, Oct., pp. 740-748.

M. Veselcic, S. Herion, R. Puthli, (2008) Selection of buttwelded connections for joints between tubulars and cast steel nodes under fatigue loading, Proceedings of the 12th International Symposium on Tubular Structures; Taylor \& Francis, London, United Kingdom

Borges, L., (2008). Size effects in the fatigue behaviour of tubular bridge joints, Ph.D. Thesis, Thesis EPFL n ${ }^{\circ} 4142$, Swiss Federal Institute of Technology (EPFL), Lausanne.

Lotsberg, I., (2009). Stress concentrations due to misalignment at butt welds in plated structures and at girth welds in tubulars, Int. Journal of Fatigue, vol. 31,N 8-9, pp. 1337 - 1345

Schumacher, A., Costa Borges, L., Nussbaumer, A., (2009). A critical examination of the size effect correction for welded steel tubular joints, Int. J. of Fatigue, Elsevier Ltd., vol. 31, pp. 1422-1433.

SNF, (2009). Swiss National Fund, Modelling of micro- and macro-structural size effects in the fatigue of welded tubular structures, grant no 200021-112014, 2006-2009.

Veselcic, M., Herion, S., and Puthli, R., (2009). Selection of butt welding methods for joints betweeen tubular steel and steel castings under fatigue loading, Proceedings Tubular Structures XII, held in Shanghai 8-10 oct. 2008, eds. Shen, Chen and Zhao, CRC press, Taylor \& Francis group, London, pp. 499-506.

P591, (2010). Wirtschaftliches Bauen von Straßen- und Eisenbahnbrücken aus Stahlhohlprofilen, Final report, Project FOSTA P591, Forschungsvereinigung Stahlanwendung e. V., Düsseldorf, Germany.

Nussbaumer, A, Herion, S., Veselcic, M., Dietrich, R., (2010). "New S-N curves for details in bridges with steel truss tubular superstructure," Proceedings of the 13th International Symposium on Tubular Structures; CRC Press/Balkema, Netherlands
VSS578 (2004). Schumacher, A., Sturm S., Walbridge, S., Nussbaumer, A. and Hirt, M. A., Fatigue design of bridges with welded circular hollow sections, Research mandate 88/98, Swiss federal highway administration, EPFL, ICOM, Lausanne (earlier published as report ICOM 489E, 2003).

EN 287: 2004. Qualification test of welders - Fusion welding Part 1: Steels

EN 1369. 1997. Founding, Magnetic particle Inspection

EN 1370. 1997. Founding, Surface roughness inspection by visual tactile comparators

EN 1371-1. 1997. Founding, Liquid penetrant inspection - Part 1: Sand, gravity die and low pressure castings

EN 1559-1. 1997. Founding, Technical conditions of delivery

EN 1559-2. 1997. Founding, Technical conditions of delivery, Part 2: Additional requirements for steel castings

DIN 1681. 1985. Steel castings for general purposes; technical delivery conditions

EN 1993-1-1. 1993. Design of steel structures - Part 1-1: General rules and rules for buildings

EN 1993-1-9. 2005. Design of steel structures - Part 1-9: Fatigue

EN 10210. 2006. Hot finished structural hollow sections of non-alloy and fine grain steels

EN 10293. 2005. Steel castings for general engineering uses

EN 12680. 2003. Founding - Ultrasonic inspection - Part 1: Steel castings for general purposes

EN 12681. 2003. Founding - Radiographic inspection

EN 17182: Steel castings with improved weldability and toughness for general purposes, DIN, Mai 1992

EN 17205. 1992. Quenched and tempered steel castings for general purposes

EN ISO 5817. 2003. Welding - Fusion-welded joints in steel, nickel, titanium and their alloys (beam welding excluded) Quality levels for imperfections

EN ISO 9692. 2004. Welding and allied processes - Recommendations for joint preparation

AD HP 5/3 and App.1. 2002. Manufacture and testing of joints - Non-destructive testing of welded joints,

CIDECT Report - Project 7W. 2007. Fatigue of End-To-End CHS Connections, Sixth Interim Report, University of Karlsruhe

CIDECT, 2009. Project 7W, Fatigue of end-to-end connections, University Karlsruhe, 2006-09.

CIDECT recommendations, 2000. Zhao, X. L., Herion, S., Packer, J. A. and al. Design guide for circular and rectangular hollow section joints under fatigue loading. CIDECT, Comité International pour le développement et l'étude de la construction tubulaire, guide no 8, TüV-Verlag Rheinland, Köln.

EN 10210, 1997. Hot finished structural hollow sections of non-alloy and fine grain structural steels, Part 1: technical delivery requirements and Part 2: tolerances, dimensions and sectional properties, Brussels, CEN.

EN 10293, 2005. Steel castings for general engineering uses, Brussels, CEN.

EN 1993-1-9, 2005. Design of steel structures, Part 1.9: fatigue strength of steel structures, Brussels, CEN.

DIN 17182, 1992. General-purpose steel castings with enhanced weldability and higher toughness; technical delivery conditions, Deutsches Institut für Normung E.V., Berlin. 